\title{
Lactobacillus pentosus DSM 16366 starter added to brine as freeze-dried and as culture in the nutritive media for Spanish style green olive production
}

\author{
By Cidália Peres ${ }^{a *}$, Luis Catulo ${ }^{a}$, Dulce Brito ${ }^{a}$ and Cristina Pintado ${ }^{a}$ \\ a Instituto Nacional dos Recursos Biológicos/Instituto Nacional de Investigaçao \\ Agrária, Apartado 6, 7350-591 Elvas, Portugal ("cidaliaperes@gmail.com)
}

\section{RESUMEN}

Utilización de inóculo de Lactobacillus pentosus DSM 16366 liofilizado y en suspensión en caldo nutritivo para producción de aceitunas verdes estilo sevillano.

En este trabajo se empleo el inóculo Lactobacillus pentosus DSM 16366 liofilizado y en caldo nutritivo para preparación de aceitunas "Azeiteira" tipo verde, estilo sevillano. En las salmueras inoculadas se observó una acidificación más rápida y reducción del periodo de supervivencia de las Enterobacteriaceae, especialmente cuando se aplicó el inóculo en caldo nutritivo.

PALABRAS CLAVE: Aceitunas - Fermentación - Inóculo - Lactobacillus pentosus - Olea europaea.

\section{SUMMARY}

Lactobacillus pentosus DSM 16366 starter added to brine as freeze-dried and as starter culture in the nutritive media for Spanish style green olive production.

Lactobacillus pentosus DSM 16366, a strain originally isolated from olive fermentation, was used as a starter culture for "Azeiteira" the preparation of Spanish style green olives. Inoculum was added to the fermentors as a freezedried starter culture or as a culture in the nutritive media. Lactic acid fermentation induction produced a more rapid acidification of brines and reduced the survival period of Enterobacteriaceae compared with the uninoculated process. The best results were obtained using the nutritive media as a culture carrier rather than the freeze-dried starter.

KEY-WORDS: Fermentation - Lactobacillus pentosus Olea europaea - Olives - Starter culture.

\section{INTRODUCTION}

Modern large scale production of table olives is focused on the use of defined strain starter systems to ensure quality and consistency in the final product. Lactic acid bacteria have been exploited because of their ability to produce desirable changes in organoleptic attributes, improve shelflife and enhance food safety (Sánchez et al., 2001; de Castro et al., 2002; Chorianopoulos et al., 2005). In Spanish style green olive fermentation, as a consequence of the alkaline treatment, $\mathrm{pH}$ values during the first days after brining are not favorable for the growth of lactobacilli, whereas potential spoilage microorganisms can proliferate and spoil the product.

Lactobacillus plantarum and Lactobacillus pentosus have been known to play an important role in many spontaneous processes of table olive fermentation. Therefore, these species have been used as starter cultures to improve the microbiological control of the process and to produce consistently high quality table olives (Sánchez et al., 2001; de Castro et al., 2002; LealSánchez et al., 2003; Panagou et al., 2003; Chorianopoulos et al., 2005; Lamzira et al., 2005). The inhibitory action of lactic acid bacteria is due to the accumulation of main primary metabolites (lactic and acetic acids, ethanol and carbon dioxide) as well as to the production of other microbial compounds (formic and benzoic acids, hydrogen peroxide, diacetyl, acetoin and bacteriocins).

Lactobacillus pentosus DSM 16366, originally isolated from Spanish style olive fermentation brines was shown to produce the highest bacteriocin titers in environmental conditions that resembled green table olive fermentation (Delgado et al., 2005), suggesting its technological interest as a starter for table olives.

The objectives of the present study, concerning green table olives of the Portuguese Azeiteira cultivar, were to assess chemical and microbial fermentation profiles and to study the effect of Lactobacillus pentosus DSM 16366 as freeze-dried cells and as culture in nutritive media on the development of fermentation and final product quality. 


\section{MATERIALS AND METHODS}

\subsection{Preparation of olives}

Green olives of the Portuguese cultivar Azeiteira (Olea europaea) were harvested from an olive grove in the Alentejo Northeast area. The steps of Spanish-style processing were as follows: Olives were submitted to an alkali treatment $(1.5 \% \mathrm{w} / \mathrm{v})$ for 6 hours until penetration of $\mathrm{NaOH}$ reached approximately $2 / 3$ of the flesh (c.a. 6 hours) and then washed with tap water twice for 4 and 12 hours. Fruits were placed in brine $(8.0 \% \mathrm{NaCl}, \mathrm{w} / \mathrm{v})$. It is very important that all the olives have been submitted to the exactly same procedure, since alkaline treatment and washing are crucial for subsequent fermentation. Then, the fermentors were placed in a room maintained at $30^{\circ} \mathrm{C}$.

Lactobacillus pentosus DSM 16366, originally isolated from green olive fermenting brines, was used as a starter culture. The inoculation was carried out suspending freeze-dried cells into brine from the corresponding fermentor and left for $4 \mathrm{~h}$ to rehydrate or with an overnight culture in Man Rogosa and Sharpe broth (MRS) (Oxoid, Hampshire, England). Lactobacillus pentosus DSM 16366 was added to brines giving a population in

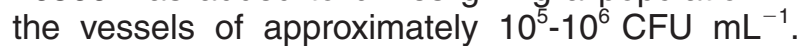
Inoculation took place at day 5 of fermentation, when brine $\mathrm{pH}$ was c.a. 6 (Delgado et al., 2005). Spontaneous fermentation by the environmental microbiota represented the control treatment. Trials were prepared in duplicate in $30 \mathrm{~L}$ plastic containers.

At the first and fifth days of fermentation and each week for a further 50 days, samples of brine were aseptically withdrawn from the centre of the fermentation containers to analyze microbial and chemical parameters in order to draw fermentation profiles.

\subsection{Microbial growth in brines}

Brine suspensions were serially diluted and plated on selective media for counting purposes. Enterobacteriaceae colonies were counted on crystal-violet neutral red bile glucose agar (Merck, Darmstad, Germany) incubated at $30{ }^{\circ} \mathrm{C}$ for $24 \mathrm{~h}$. Lactic acid bacteria were numbered on Man Rogosa and Sharpe agar (MRS) (Oxoid, Hampshire, England), supplemented with $0,01 \%$ (w/v) sodium azide (Sigma-Aldrich, Madrid, Spain) at $30{ }^{\circ} \mathrm{C}$ for 72 hours. Fungi were counted after 72 $\mathrm{h}$ of incubation at $28{ }^{\circ} \mathrm{C}$ on dichloran-glycerol (DG18) agar base (Oxoid, Hampshire, England) with chloramphenicol selective supplement (Oxoid, Hampshire, England).

\subsection{Chemical profile of brines}

Along with the microbiological analyses, brine samples from each fermentor were analyzed for $\mathrm{pH}$, free acidity, and $\mathrm{NaCl}$ concentration (Díez et al., 1985). Free acidity was expressed as lactic acid percentage in brine $(\mathrm{w} / \mathrm{v})$.

\subsection{Organoleptic evaluation}

After 60 days of fermentation, representative samples were presented to a 5-member trained panel which was assigned to assess samples' overall appreciation on a 1 to 9 rating scale.

\subsection{Statistical analysis}

Mean and standard deviation values of the different parameters were plotted.

\section{RESULTS AND DISCUSSION}

This experiment was performed in three consecutive seasons and fermentation profiles were essentially the same. Results from one set of fermentations are shown below.

Microbial and chemical spontaneous fermentation profiles of "Azeiteira" Spanish-type green olives, shown in Figures 1-5, can be characterized in the so-called three successive phases. Initially, Enterobacteriaceae predominated and brine $\mathrm{pH}$ decreased to a value approximately 6.0. During the second phase, lactobacilli and fungi developed quickly, and Enterobacteriaceae decreased until they disappeared completely at a $\mathrm{pH}$ around 4.2. In the third phase, lactic acid bacteria $\left(10^{9} \mathrm{CFU} \mathrm{mL}{ }^{-1}\right)$ abounded and coexisted with fungi $\left(10^{4} \mathrm{CFU} \mathrm{\textrm {mL } ^ { - 1 }}\right)$.

Throughout fermentation there was no $\mathrm{NaCl}$ addition. In brines, by the diffusion phenomenon between brine and fruit, salt concentration declined until the equilibrium was achieved exhibiting values around $4 \%$ (data not shown). In fact, salt concentration at day 1 was between 4.7 and $5.1 \%$ in all fermentors, which is a concentration easily tolerated by most strains of lactobacilli from olive fermentations including L. pentosus DSM 16366 (Delgado et al., 2005).

The results revealed an initial rapid drop in $\mathrm{pH}$ during the first 12 days of fermentation, followed by stabilization around 4 units and a negligible rate of drop until the end of the fermentation, achieving 3.8-3.9 pH units (Figure 1). The sharp decrease of $\mathrm{pH}$ is consistent with the remarkable increase in the lactic acid bacteria population and free acidity as described below (Figure 2 and Figure 3). Lactic acid bacteria produce mainly lactic acid; and to a lesser extent other acids, leading to a pH drop (Sánchez et al., 2000, 2001; de Castro et al., 2002; Panagou et al., 2003; Chorianopoulos et al., 2005).

In all fermentors, free acidity remained very low during the first five days (less than $0.10 \%$ ) and afterwards raised rapidly (Sánchez et al., 2001; LealSánchez et al., 2003). At 12 days of fermentation, 7 days post-inoculation, free acidity was $0.61 \%$ when 


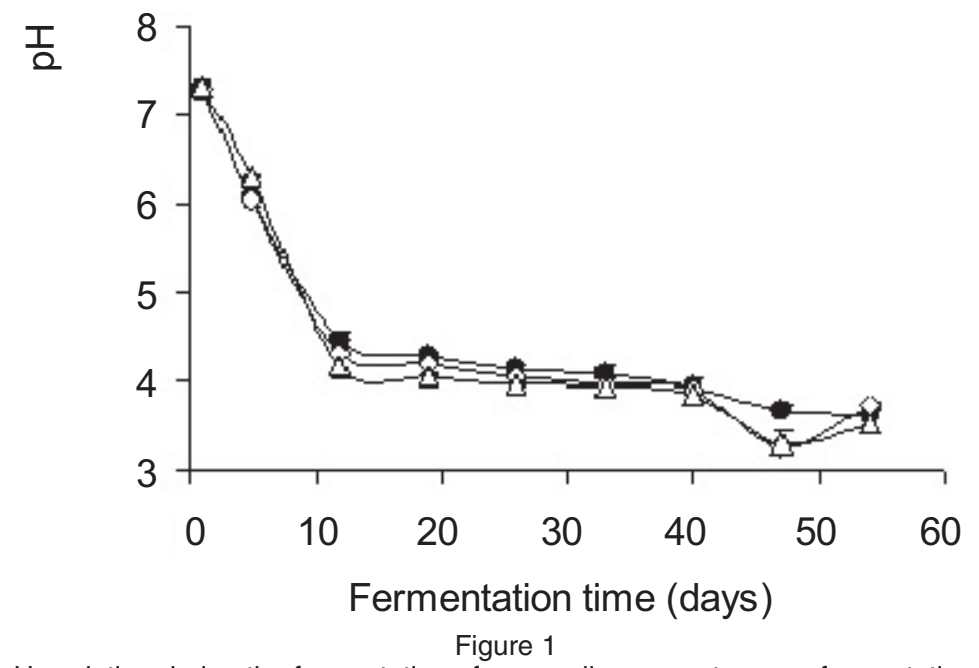

$\mathrm{pH}$ evolution during the fermentation of green olives: spontaneous fermentation (•) and induced lactic acid fermentation by adding Lactobacillus pentosus DSM 16366 as freeze-dried cells $(\diamond)$ and culture in nutritive media $(\Delta)$.

the inoculum carrier was nutritive media, whereas freeze-dried starter application and spontaneous fermentation showed free acidity levels above $0.6 \%$ only after 26 and 33 days of fermentation, respectively (Figure 2). Therefore, induced lactic acid fermentation by Lactobacillus pentosus DSM 16366 culture accelerated acidification during the second stage of fermentation, thus reducing the risk of spoilage, as previously found in earlier studies on green olives using $L$. pentosus and $L$. plantarum starters (Sánchez et al., 2000, 2001; Leal-Sánchez et al., 2003; Panagou et al., 2003). The positive effect of MRS inoculum carrier could be explained by its protective effect on $L$. pentosus cells, as previously observed in $L$. plantarum in the presence of other stressing conditions (Durán Quintana et al., 1994).
The addition of growth factors to the ecosystem, notably vitamins, amino acids or trace elements could also play a role (Ruiz-Barba and JiménezDíaz, 1994).

A remarkable increase in lactic acid bacteria occurred during the week after inoculation, this increase being smaller in spontaneous fermentation (Figure 3). Throughout the second month of fermentation, a similar pattern and moderate fluctuation around $10^{9} \mathrm{CFU} \mathrm{\textrm {mL } ^ { - 1 }}$ lactic acid bacteria were recorded for all fermentors (Sánchez et al., 2000, 2001). Nevertheless, it must be stressed that this delay at the onset of fermentation, when the risk of spoilage due to Enterobacteriacea or butyric-acid-producing clostridia is highest, implies a higher likelihood of

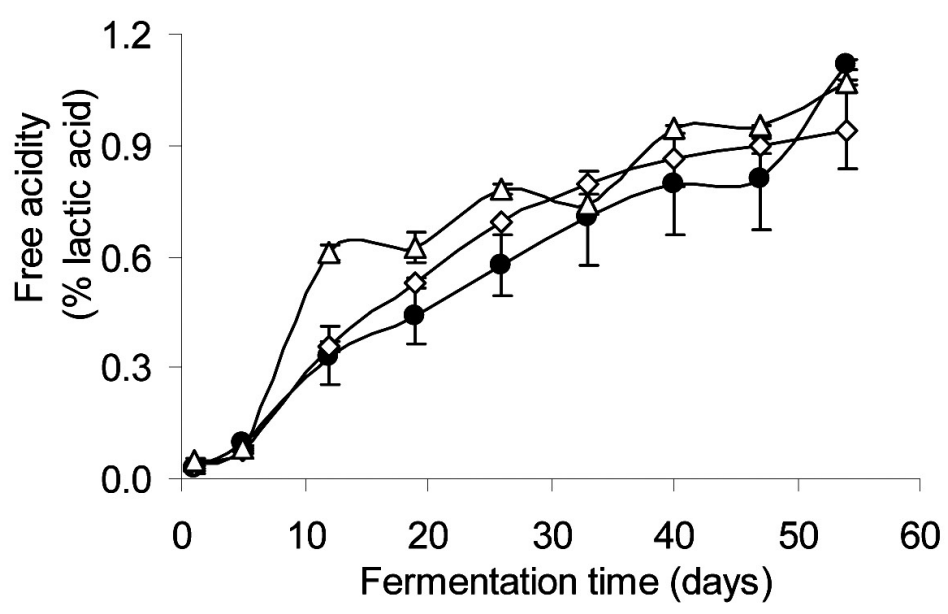

Figure 2

Free acidity evolution during the fermentation of green olives: spontaneous fermentation $(\bullet)$ and induced lactic acid fermentation by adding Lactobacillus pentosus DSM 16366 as freeze-dried cells $(\diamond)$ and culture in nutritive media $(\Delta)$. 


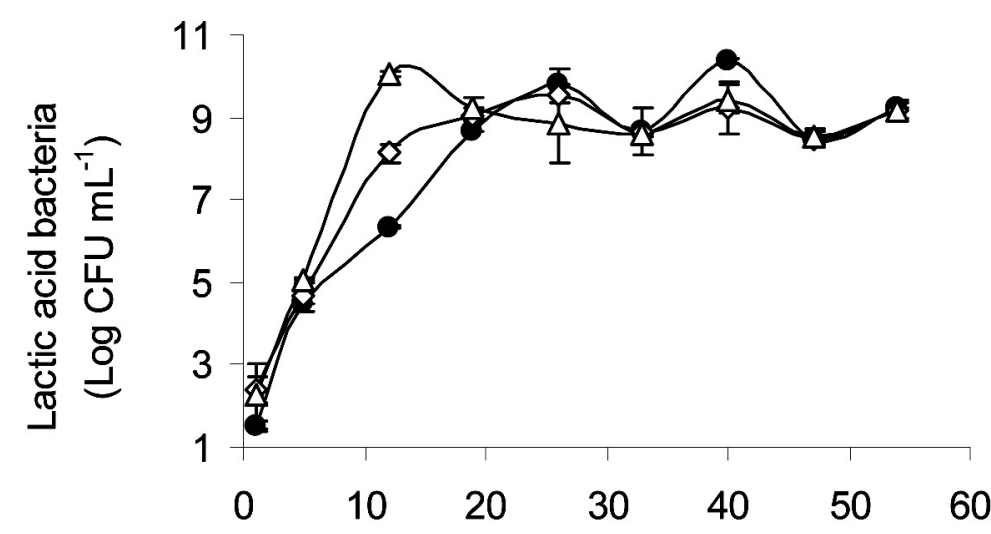

Fermentation time (days)

Figure 3

Lactic acid bacteria population evolution during the fermentation of green olives: spontaneous fermentation $(\bullet)$ and induced lactic acid fermentation by adding

Lactobacillus pentosus DSM 16366 as freeze-dried cells $(\diamond)$ and culture in nutritive media $(\Delta)$.

spoilage if inoculation is not carried out. Furthermore, Lactobacillus pentosus DSM 16366 bacteriocin production could be a relevant factor in strain establishment and may contribute to the control of microbiological fermentation (Delgado et al., 2005). Moreover, the predominance of the lactic population in the olive brine is important to inhibit the fermentative metabolism of yeasts that produce bloaters (Lamzira et al., 2005).

Enterobacteriaceae showed an increase within the first 5 days of fermentation, which was followed by a noticeable decrease until they achieved

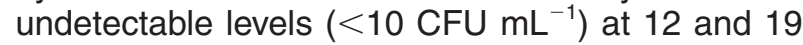
days using culture and freeze-dried cell starters, respectively, and 26 days in the control (Figure 4). The reduction of this microbiota coincided with the free acidity rising above $0.5 \%$ and the $\mathrm{pH}$ dropping below 4.2 (Figure 1 and Figure 2). Enterobacteriaceae were inactivated faster in started lactic fermentation than in the control
(Sánchez et al., 2000; de Castro et al., 2002; Lamzira et al., 2005), especially when nutritive media was used as starter carrier, confirming the advantage of using Lactobacillus pentosus DSM 16366 to reduce the likelihood of spoilage.

With regard to fungi growth (Figure 5), after the $19^{\text {th }}$ day of brining, an early population increase seemed to occur in fermentors added by starter culture, but it soon disappeared, and the population, in both inoculated and uninoculated vessels, achieved similar values (Sánchez et al., 2000; 2001; Leal-Sánchez et al., 2003).

At the end of the process, spontaneous and induced fermentation revealed a similar lactic acid bacteria $\left(10^{9} \mathrm{CFU} \mathrm{mL}^{-1}\right)$ and fungi $\left(10^{4} \mathrm{CFU} \mathrm{mL}^{21}\right)$, as well as $\mathrm{pH}$ (3.8) and free acidity (1.0\% lactic acid) (Figures 1-5). Suitability of using L. pentosus DSM 16366 as a starter culture may be emphasized by future studies focusing on the main fermentation substrates and end-products, which could reveal an

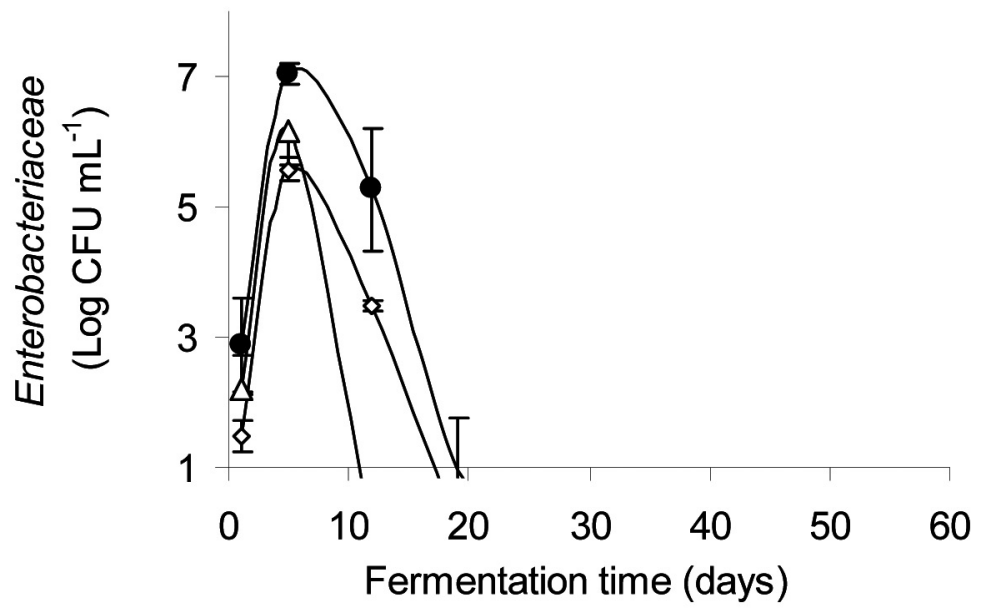

Figure 4

Enterobacteriaceae evolution during the fermentation of green olives: spontaneous fermentation $(\bullet)$ and induced lactic acid fermentation by adding Lactobacillus pentosus DSM 16366 as freeze-dried cells $(\diamond)$ and culture in nutritive media $(\Delta)$. 


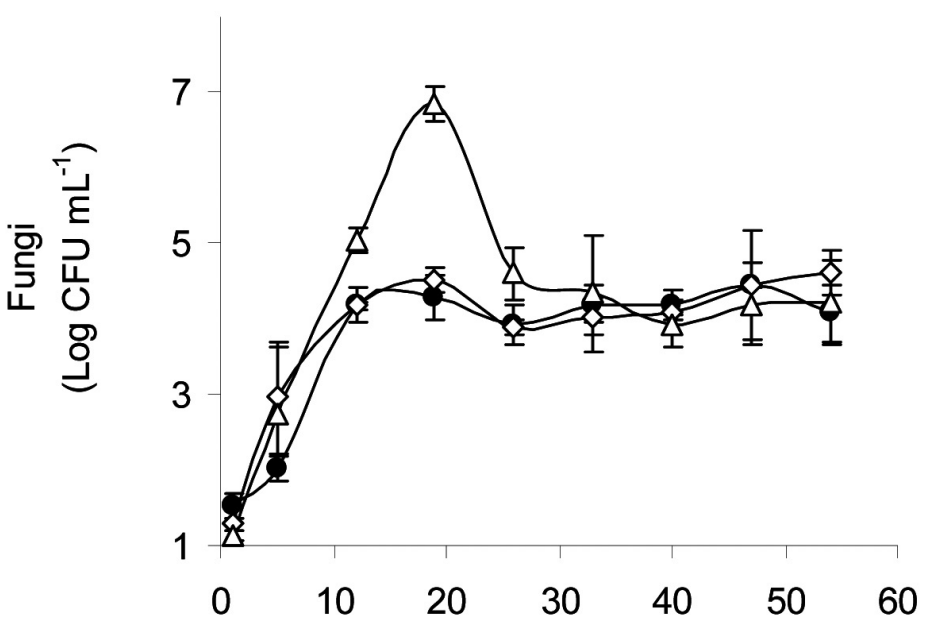

Fermentation time (days)

Figure 5

Fungi evolution during the fermentation of green olives: spontaneous fermentation $(\bullet)$ and induced lactic acid fermentation by adding Lactobacillus pentosus DSM 16366 as freeze-dried cells $(\diamond)$ and culture in nutritive media $(\Delta)$.

improved and more predictable fermentation process, as well as a greater safety and a reduced hygiene risk. No differences were found in the overall organoleptic evaluation of inoculated and naturally fermented olives (data not shown). Trials to confirm these results at industrial scale are underway.

\section{CONCLUSIONS}

At the beginning of fermentation, a beneficial effect could be seen on microbial growth and chemical characteristics of brines, namely Enterobacteriaceae, lactic acid bacteria and free acidity. Enterobacteriaceae were inactivated faster in inoculated fermentors than in controls, illustrating the advantage of using Lactobacillus pentosus DSM 16366 to reduce the likelihood of spoilage. The best results were attained using nutritive media as pure culture carrier rather than freeze-dried cells.

\section{ACKNOWLEDGEMENTS}

This work is part of the research project $P O$ AGRO DE\&D-Project n. 463.

\section{REFERENCES}

Chorianopoulos NG, Boziaris IS, Stamatiou A, Nychas GJE. 2005. Microbial association and acidity development of unheated and pasteurized green-table olives fermented using glucose or sucrose supplements at various levels. Food Microbiol. 22, 117-124.

de Castro A, Montaño A, Casado FJ, Sánchez, AH, Rejano L. 2002. Utilization of Enterococcus casseliflavus and Lactobacillus pentosus as starter cultures for Spanish-style green olive fermentation. Food Microbiol. 19, 637-644.
Delgado A, Brito D, Peres C, Noé-Arroyo F, GarridoFernández A. 2005. Bacteriocin production by Lactobacillus pentosus B96 can be expressed as a function of temperature and $\mathrm{NaCl}$ concentration. Food Microbiol. 22, 521-528.

Díez MJF, Ramos RC, Fernández AG, Cancho FG, Pellissó FG, Vega, MN, Moreno AH, Mosquera MIM, Navarro LR, Quintana MCD, Roldán PS, García, PG., Gómez-Millán AC. 1985. Metodología, in Biotecnología de la Aceituna de Mesa, CSIC, Madrid, Spain, pp. 385-453.

Durán Quintana MC, García P, Brenes M, Garrido A. 1994. Induced lactic acid fermentation during the preservation stage of ripe olives from Hojiblanca cultivar. J. Appl. Bacteriol. 76, 377-382.

Lamzira Z, Asehraou A, Brito D, Oliveira M, Faid M, Peres C. 2005. Reducing the bloater spoilage during lactic fermentation of Moroccan green olives. Food Technol. Biotechnol. 43, 373-377.

Leal-Sánchez MV, Ruiz-Barba JL, Sánchez AH, Rejano L, Jiménez-Díaz R, Garrido A. 2003. Fermentation profile and optimization of green olive fermentation using Lactobacillus plantarum LPCO10 as a starter culture. Food Microbiol. 20, 421-430.

Panagou EZ, Tassou CC., Katsaboxakis, CZ. 2003. Induced lactic acid fermentation of untreated green olives of the Conservolea cultivar by Lactobacillus pentosus. J. Sci. Food Agric. 83, 667-674.

Ruiz-Barba JL, Jiménez-Díaz R. 1994. Vitamin and amino acid requirements of Lactobacillus plantarum strains isolated from green olive fermentations. J. Appl. Bacteriol. 76, 350-355.

Sánchez, A-H, de Castro A, Rejano L, Montaño A. 2000. Comparative study on chemical changes in olive juice and brine during green olive fermentation. J. Agric. Food Chem. 48, 5975-5980.

Sánchez AH, Rejano L, Montaño A, de Castro A. 2001. Utilization at high $\mathrm{pH}$ of starter cultures of lactobacilli for Spanish-style green olive fermentation. Int. J. Food Microbiol. 67, 115-122. 